\title{
Caso clínico radiológico pediátrico
}

\author{
SANTIAGO CHANG S.*, ALEJANDO BUSTOS A.** y CRISTIÁN GARCÍA B.***
}

Pediatric radiological clinical case

\section{Historia Clínica}

Preescolar de 5 años, sexo masculino, previamente sano, sin antecedentes broncopulmonares ni epidemiológicos de importancia, que consulta por fiebre de hasta $38^{\circ} \mathrm{C}$, de 4 semanas de evolución. Al examen, destaca aumento de volumen de las partes blandas de la pared anterior del hemitórax derecho y deficiente higiene bucal.

Se solicita radiografía $(\mathrm{Rx})$ de tórax en proyecciones anteroposterior y lateral (Figura 1) y tomografía computada de tórax con contraste endovenoso (Figura 2).

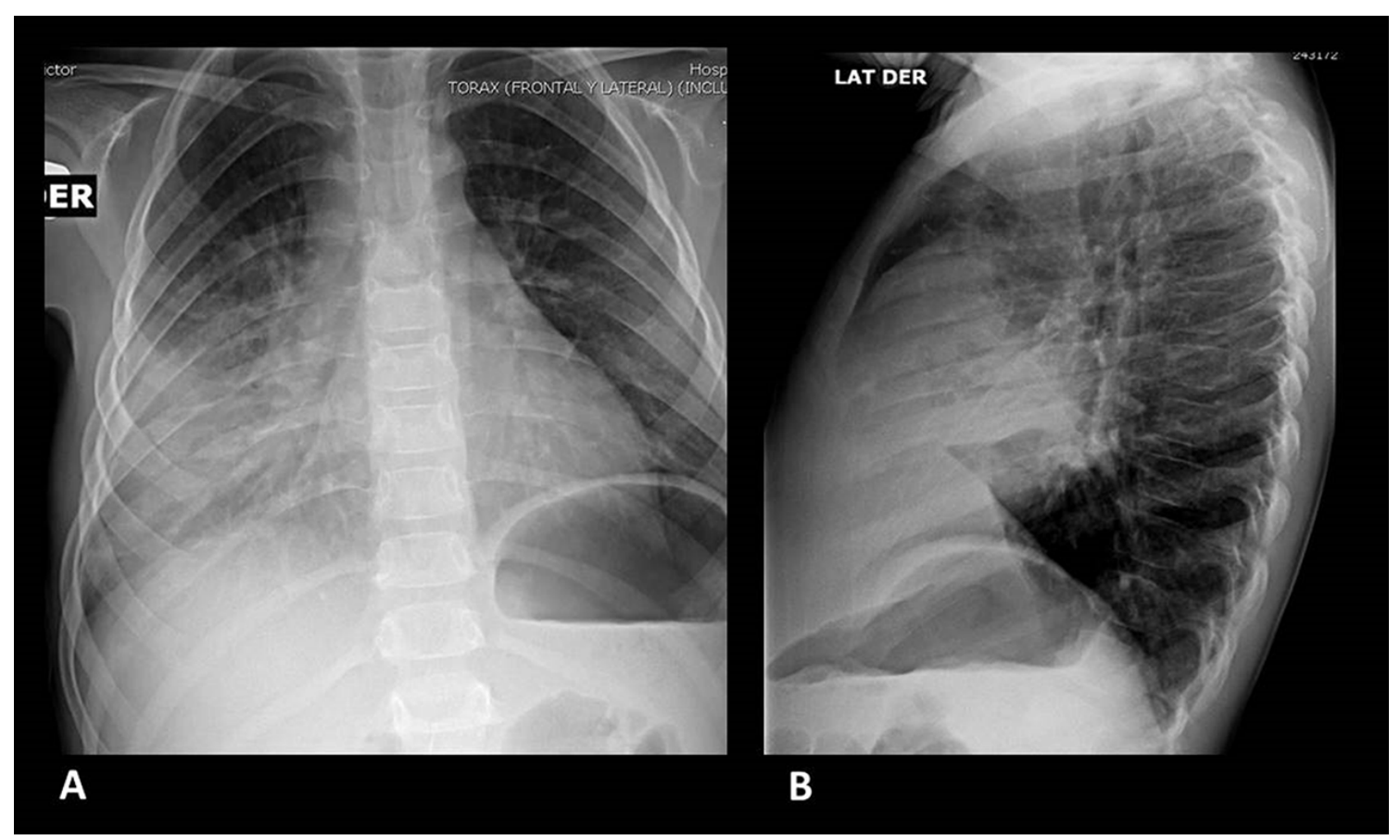

Figura 1. Radiografía de tórax póstero-anterior (A) y lateral (B).

* Médico Radiólogo. Becado en Radiología Pediátrica, Departamento de Radiología, Facultad de Medicina, Pontificia Universidad Católica de Chile. Dirección actual: Servicio de Radiología, Hospital de Especialidades Pediátricas, Caja de Seguridad Social. Ciudad de Panamá. Panamá.

** Hospital Dr. Hernán Henríquez Aravena de Temuco. Temuco, Chile.

*** Profesor Titular, Departamentos de Radiología y Pediatría, Facultad de Medicina, Pontificia Universidad Católica de Chile. Santiago, Chile. 


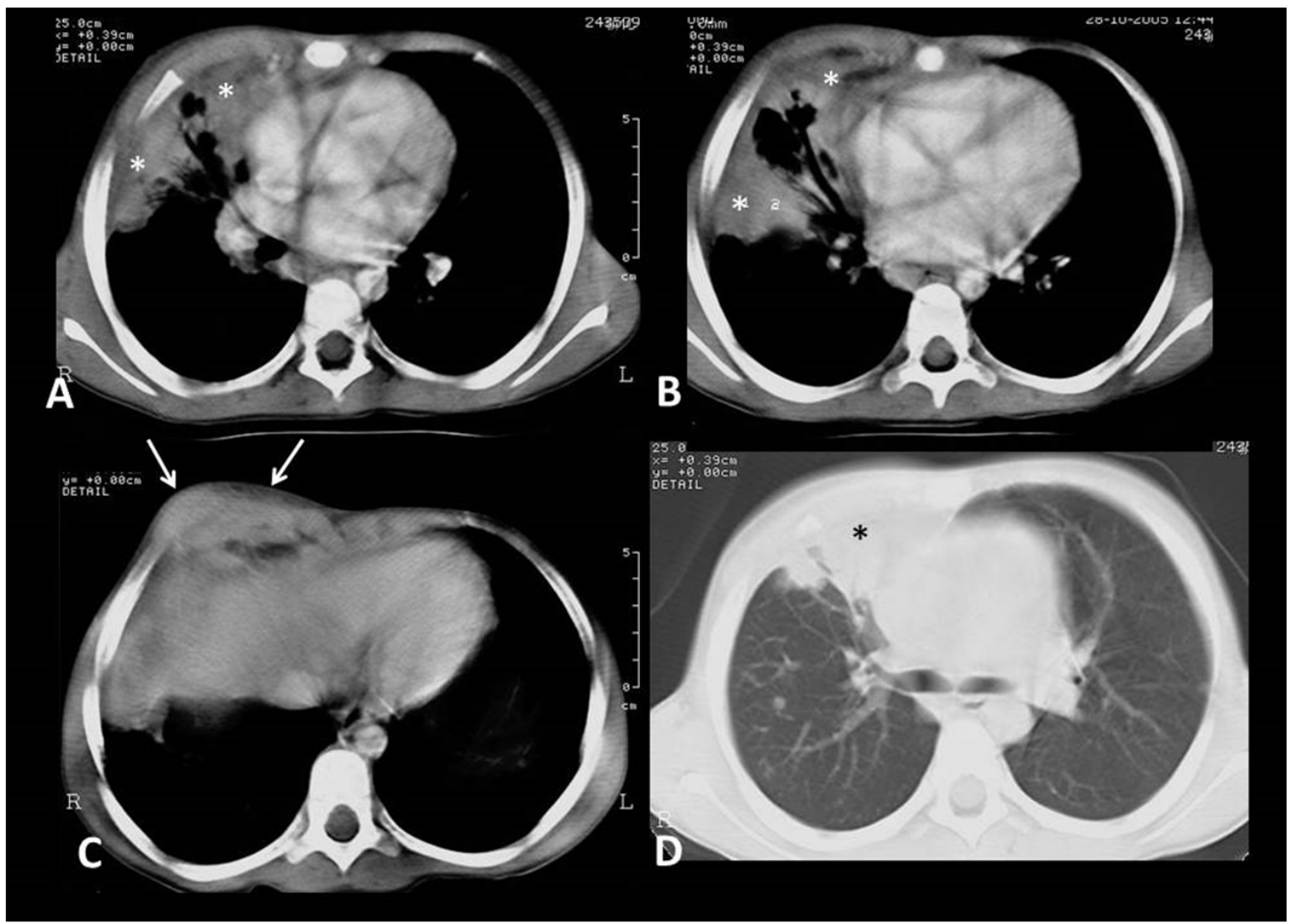

Figura 2. Tomografía computada de tórax, con contraste endovenoso y en cortes axiales seleccionados, con ventana mediastínica o de partes blandas (A, B, C) y ventana pulmonar (D).

\section{¿Cuál sería su diagnóstico?}

\section{Hallazgos radiológicos}

La radiografía de tórax (Figura 1) muestra una opacidad con broncograma aéreo y bordes relativamente mal definidos, en el lóbulo medio derecho, que contacta el mediastino y la pared anterior del hemitórax de ese lado y determina borramiento del borde derecho del corazón. No hay signos de derrame pleural ni se observan otras imágenes pulmonares patológicas.

La tomografía computada de tórax, con contraste endovenoso en ventanas de mediastino (A, B, C) y pulmón (D) (Figura 2), muestra una consolidación que compromete el lóbulo medio del pulmón derecho, contacta el margen lateral derecho del mediastino $\left(^{*}\right)$ y se extiende hacia las partes blandas de la pared anterior del tórax, las que están engrosadas (flechas). La lesión se refuerza en forma heterogénea con el contraste y hay además engrosamiento focal de la pleura $(*)$. No se demostró compromiso óseo.
El estudio histológico de la lesión mostró una Actinomicosis pulmonar.

\section{Diagnóstico}

Actinomicosis pulmonar.

\section{Discusión}

La actinomicosis es una infección bacteriana, producida por distintas especies de la familia Actinomyces, del tipo gram positivo, predominantemente anaerobio, ubicuo en la naturaleza y además un comensal que coloniza habitualmente la cavidad oral, vías aéreas y el tracto gastrointestinal ${ }^{1-3}$. Se han caracterizado catorce especies de Actinomyces, aunque únicamente seis han mostrado ser patógenos en seres humanos, siendo A. israelii el más frecuente, seguido de $A$. naes- 
lundi, A. odontolyticus, A. viscosus, A. meyeri y A. gerencseriae ${ }^{1}$.

Las especies de Actinomyces son poco virulentas y su principal mecanismo patogénico es la ruptura de las barreras mucosas secundarias a infecciones previas, cuerpos extraños, traumatismos o cirugía. Una vez que se superan estas barreras, se puede producir una infección local, que progresa lentamente por contigüidad, siendo rara su diseminación hematógena. Es típica la extensión a tejidos vecinos sin respetar las barreras anatómicas, incluyendo planos fasciales y canales linfáticos ${ }^{2}$.

Es una enfermedad rara en niños. La afectación pulmonar aparece como un cuadro de condensación pulmonar subaguda o crónica que no mejora con el tratamiento antibiótico convencional. La complicación clásica es el compromiso de la pared torácica y fistulización, con "supuración en gránulos de azufre" que ocurre con menor frecuencia en la actualidad ${ }^{4}$.

La afectación torácica ocurre en aproximadamente el $15 \%$ del total de los casos y es más común en niños inmunodeprimidos, con retraso mental o internados en instituciones donde el cuidado dental es deficiente ${ }^{3,5,6}$. La aspiración de secreciones nasofaríngeas o de la región bucal en niños con higiene oral deficitaria es el fenómeno patogénico primario más frecuente.

Este cuadro no es considerado habitualmente en el diagnóstico diferencial de la patología pulmonar pediátrica, y el diagnóstico se establece en muchas ocasiones después de haber agotado un importante número de pruebas complementarias incluyendo la biopsia pulmonar a cielo abierto.

La radiografía de tórax presenta un compromiso periférico y la neumopatía disminuye de tamaño en forma relativamente lenta, con tratamiento adecuado. En la tomografía computada de tórax, se observa con mayor frecuencia una consolidación focal periférica o en parches, derrame pleural, adenopatías hiliares reactivas y puede existir compromiso de las partes y de la parrilla costal, con signos de erosión ósea. La consolidación pulmonar con compromiso pleural y de la pared torácica es una tríada característica de actinomicosis i, $^{3,7}$.

De esta manera, la hipótesis de actinomicosis debe considerarse en el diagnóstico diferencial de las masas torácicas, en especial aquellas que comprometen la pared del tórax, incluso en ausencia de factores de riesgo, lo que es importante para guiar los estudios microbiológicos e histo$\operatorname{lógicos}^{8-11}$.

El diagnóstico diferencial debe incluir las neoplasias pulmonares, neoplasias óseas, infec- ción por micobacterias, aspergilosis y absceso pulmonar, dependiendo de la edad. En especial debe considerarse la posibilidad de un tumor óseo, específicamente el sarcoma de Ewing, con compromiso de la pared del tórax y extensión hacia el espacio extrapleural ${ }^{12,13}$.

El diagnóstico se sospecha con la historia clínica, los estudios de imágenes y se confirma por la identificación de $A$. israelii u otras especies de Actinomyces mediante microscopía y cultivo de expectoración, idealmente obtenido por fibrobroncoscopía o biopsia.

Además de la forma torácica, la Actinomicosis puede presentarse con compromiso cérvicofacial, abdominal, pelviano o en forma generalizada.

Los microorganismos del género Actinomyces son uniformemente sensibles a la penicilina y el tratamiento es generalmente una combinación de terapia antibiótica prolongada con drenaje quirúrgico. A pesar de la ausencia de datos disponibles para justificar la duración óptima del tratamiento, la mayoría de los autores recomienda tratamiento antibiótico por un período prologado, entre 6 y 12 meses, al comienzo por vía endovenosa (Penicilina G) luego por vía oral (penicilina oral o amoxicilina) y la evolución es generalmente satisfactoria ${ }^{3,8,9,14}$.

\section{Bibliografía}

1.- LLOMBART M, CHINER E, SIGNES-COSTA J, ARRIERO JM, GÓMEZ-MERINO E, ANDREU A, et al. Actinomicosis torácica: una vieja entidad con nuevas expresiones clínicas. An. Med. Interna (Madrid) 2005; 22; 124-9.

2.- RAMÍREZ F, BARRERA EC, MÉNDEZ RY. Actinomicosis pulmonar: Una enfermedad olvidada. Acta Med Colomb 2010; 35: 132-4.

3.- PEREIRA N, CUEVAS P, VALENCIA C, VEGA J, GALLEGOS I, FERNÁNDEZ JG, et al. Actinomicosis torácica como diagnóstico diferencial de neoplasia: a propósito de un caso. Rev Chilena Infectol 2012; 29: 455-8.

4.- VIDAUR NA, ALVARENGA O, VIDAUR EA. Actinomicosis torácica: presentación de un caso. Arch Argent Pediatr 2015; 113: e345-e348.

5.- WATT AJ. Chest wall lesions. Paediatr Respir Rev 2002; 3: 328-38.

6.- ORTIZ A, FERNÁNDEZ AI, ROBLAS R. Actinomicosis. Medicine 2006; 56: 3646-52.

7.- BARTLETT AH, RIVERA AL, KRISHNAMURTHY R, BAKER CJ. Thoracic actinomycosis in children: case report and review of the literature. Pediatr Infect Dis J 2008; 27: 165-9. 
8.- WHITWORTH S, JACOBS RF. Actinomycosis. In: Feigin RD, Cherry J, Demmler Harrison GJ, Kaplan SL, editors. Textbook of pediatric infectious diseases. 6th ed. Philadelphia: Sanders; 2009. p. 1880-5.

9.- GOUSSARD P, GIE R, KLING S, BEYERS N. Thoracic actinomycosis mimicking primary tuberculosis. Pediatr Infect Dis J 1999; 18: 473-5.

10.- LIN CH, LIN WC, HO YJ, CHANG CL, LIU FC, LIN CM. Pulmonary actinomycosis with remote lower chest wall involvement in an immunocompetent child. Pediatr Int 2010; 52: 129-31.

11.- CELEBI S, SEVINIR B, SARAYDAROGLU O, GURPINAR A, HACIMUSTAFAOGLU M. Pulmonary actinomycosis. Indian J Pediatr 2009; 76: 236-8.

12.- YEUNG VH, WONG QH, CHAO NS, LEUNG MW, KWOK WK. Thoracic actinomycosis in an adolescent mimicking wall tumor or pulmonary tuberculosis. Pediatr Surg Int 2008; 24: 751-4.

13.- GANESAN K, KHAN R, EISENHUT M. Pulmonary actinomycosis masquerading as a malignant lung tumor in a 9-year-old boy. Clin Pediatr (Philadelphia) 2005; 44: 181-3.

14.- FABA R, TRUJILLO S, PEÑA P, LOBOS G, WOLFF M. Actinomicosis torácica por Actinomyces odontolyticus: A case report and review of the literature. Rev. Chil. Enferm. Respir 2014; 30: 40-5.

Correspondencia a: 